\title{
Labeling of Derogatory Words in Modern Greek Dictionaries ${ }^{1}$
}

\author{
Angeliki Efthymiou, Zoe Gavriilidou and Eleni Papadopoulou \\ Democritus University of Thrace \\ aefthym@eled.duth.gr,zoegab@otenet.gr papadopoulou.lena@gmail.com
}

\begin{abstract}
The purpose of the present paper is to examine the problems of usage labeling in two Modern Greek dictionaries (the LNEG2 and the LKN) through a survey of their treatment of 'negative' terms. To do this the terms studied are drawn from various semantic groups that denote nationality, racial or cultural group, lack of intelligence, age, sexual orientation, terms addressing women, bodily effluvia, etc. The investigation of the treatment of these terms in the two Modern Greek dictionaries reveals that it is difficult to support the usage labeling distinctions they make in their prefaces for derogatory, offensive, slang or taboo words.
\end{abstract}

\section{Introduction}

This paper surveys the treatment of 'negative' terms in two Modern Greek dictionaries (the LNEG2 and the LKN) and reveals a series of problems relating to the usage labels attached to many of the entries. The terms studied come from various semantic groups such as those denoting nationality, racial or cultural group ( a Turkish region', $\sigma \kappa \nu \lambda \alpha \dot{\alpha} \alpha \pi \alpha \varsigma$ 'bloody nigger'), lack of intelligence ( $\beta \lambda \alpha \mu \mu \dot{v} v o \varsigma$

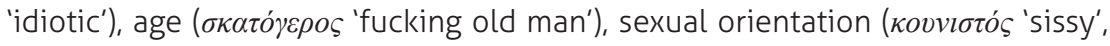

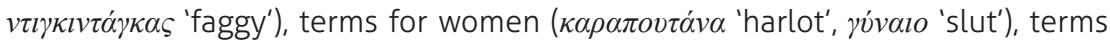
for the organs and acts of sex ( $\psi \omega \lambda \eta^{\prime}$ 'dick', $\mu \alpha \lambda \alpha \kappa i \zeta o \mu \alpha$ 'jerk off'), bodily effluvia

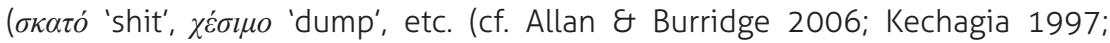

1 We would like to thank Jason Merchant, Anastasia Giannakidou, Lydia Mitits and Anna Sarafianou, for the help in the translation of data entries in English. We are also grateful to the anonymous reviewers for their useful suggestions.

\section{(cc) BY-NC-ND}


$\Xi v \delta$ ó $00 \lambda_{0}$ ऽ 2008). The paper is structured as follows. In section 2, we offer a brief overview of the relevant literature on taboo and insulting words. We also provide a brief discussion of the literature on dictionary policies in what concerns the labeling of these words. In section 3 we explain how the data of this study were selected, and we also present and discuss our results. In the last section 4, concluding remarks are given.

\section{Research Background}

In this section, we give a brief overview of the previous literature on our subject. In 2.1 we present the various categories of the offensive words, whereas in 2.2 we discuss dictionary labeling of these words.

\subsection{Taboo and Insulting Words}

Modern Greek, like other languages, contains words, which people avoid using in most contexts, because they feel them extremely embarrassing or offensive. Words of this type vary from taboo words to insults or swearing (cf. Crystal 1995; Mercury 1995; Allan \& Burridge 2006). According to Crystal (1995: 173), these three categories may overlap or coincide, but they are not identical: to call someone $\kappa \omega \dot{\lambda} \lambda o s$ 'an ass' is to use a taboo word as insult, but if used with enough emotional force could be considered an act of swearing. On the other

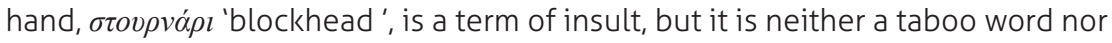
a swear word. Finally, the swear word $\kappa \alpha \tau \alpha \dot{\rho} \rho \alpha$ 'curse' is neither a taboo word nor an insult (cf. $\Xi v \delta o ́ \pi 0 v \lambda o \varsigma$ 2008).

Taboo language contains the so-called 'dirty words', i.e. mainly terms for bodily organs associated with sex, excretion and the act of sexual

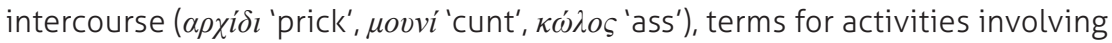
these organs ( $\kappa \alpha \nu \lambda \omega v \omega$ 'get horny'), terms for bodily effluvia issuing from

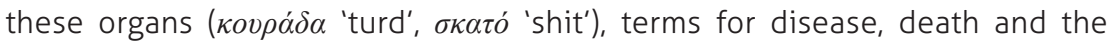

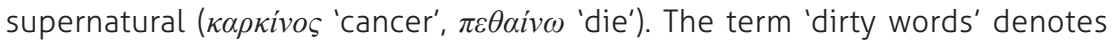
people's attitudes towards the denotations and connotations of these words, which are the most emotionally evocative of all language expressions (Allan \& Burridge 2006). People not only avoid using them in polite society, but also

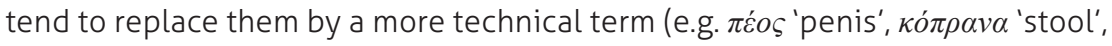

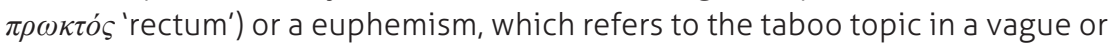
indirect way (e.g. ć $\varphi v \gamma \varepsilon$ 'be gone' instead of $\pi \dot{\varepsilon} \theta \alpha v \varepsilon$ 'died', $\pi$ ov $\lambda \dot{\alpha} \kappa l$ 'cock' instead

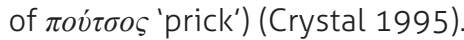

According to Crystal (1995: 173), swearing refers to the strongly emotive use of a taboo word or phrase, and its function is to express a wide range of emotions, 
like annoyance, frustration or anger. Swearing can mark also social distance, as for example when swearing in public ( $\tau$ X X solidarity marker, as when a group shares identical swearing norms (Mercury 1995; Allan \& Burridge 2006; Crystal 1995). According to the same author, swearing can be further divided into smaller categories like blasphemies, which show contempt towards God, profanities, which show contempt to holy things or people, and obscenities, which involve the expression of indecent sexuality (cf. also Mercury 1995).

Dysphemistic terms of insult (or abuse) are usually used in order to debase someone's physical appearance ( $\alpha \lambda \dot{\gamma} \gamma \alpha$ 'cow', $\kappa \alpha \rho \dot{\alpha} \varphi \lambda \alpha \varsigma$ 'bald-headed', $\pi \alpha \tau \dot{\alpha} \tau \alpha \varsigma$ 'fathead'), mental ability ( $\sigma \tau o v \rho v \alpha ́ \rho \imath$ 'blockhead'), character ( $\kappa \alpha \rho i o ́ \lambda \eta \varsigma$ 'fucker'),

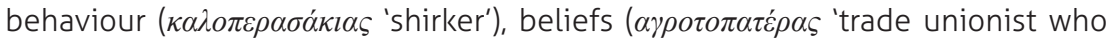
takes advantage of farmers; lit. father of farmers), and familial or social relations ( $\mu \pi \circ o \dot{\lambda} \eta \varsigma$ 'roly-poly', $\mu \alpha \mu o ́ \theta \rho \varepsilon \varphi \tau o \varsigma$ 'mama's boy') (Allan \& Burridge 2006; Mercury 1995). Furthermore, terms of abuse (or vulgarisms) can be used to devalue a thing described ( $\alpha \rho \alpha \mu \pi \alpha \varsigma^{\prime}$ 'ox-cart') (Mercury 1995)

In particular, the vast majority of the insulting words comment on someone's ugliness ( $\mu \alpha \lambda \lambda \imath \alpha \rho o$ s 'hairy', $\mu \pi \alpha \kappa \alpha \tau \dot{\prime} \lambda \alpha$ 'pot-bellied'), skin color or complexion

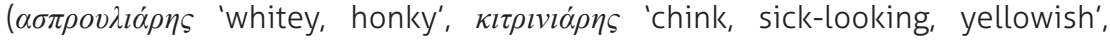

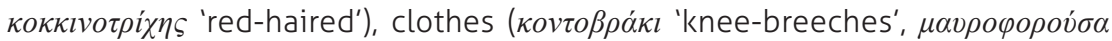

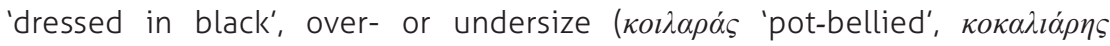

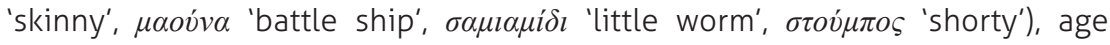

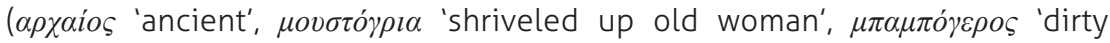

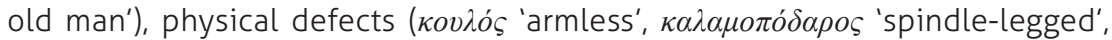

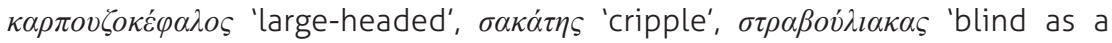

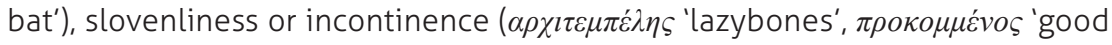

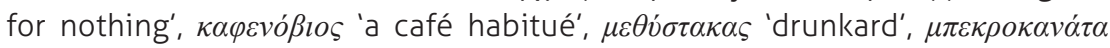

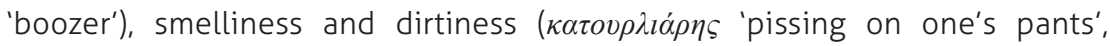

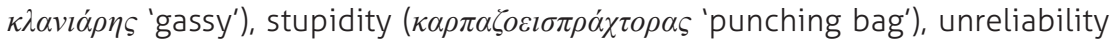

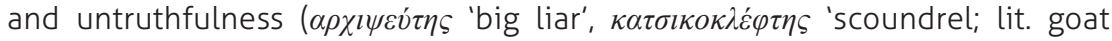

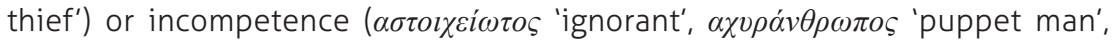

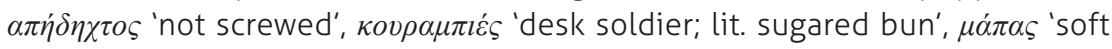
touch', $\mu \pi \dot{\alpha} \mu \imath \alpha \varsigma^{\prime}$ 'dupe'), greediness and flattery ( $\pi \varepsilon l v \alpha \lambda \varepsilon \dot{\varepsilon} o \varsigma^{\prime}$ 'ravenous', $\kappa \omega \lambda o \gamma \lambda \varepsilon i \varphi \tau \eta \varsigma$

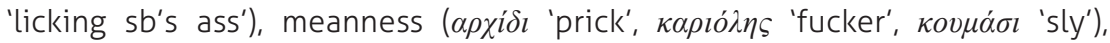

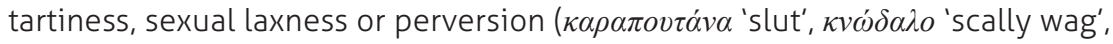

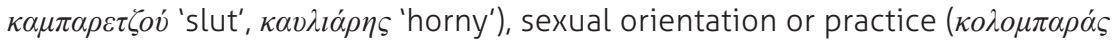

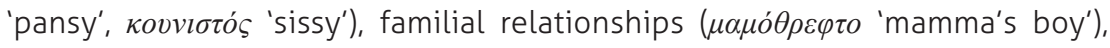

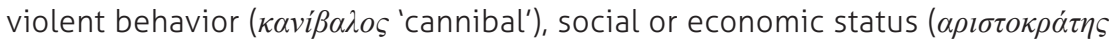

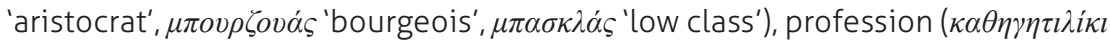
'professorship (iron.)', $\kappa \alpha \rho \alpha \beta \alpha v \alpha \dot{\varsigma}$ 'ranker', $\mu \pi \alpha \dot{\tau} \sigma o \varsigma$ 'cop', $\pi \varepsilon \theta \alpha \mu \varepsilon v \alpha \tau \zeta \dot{\eta} \varsigma$ 'grave

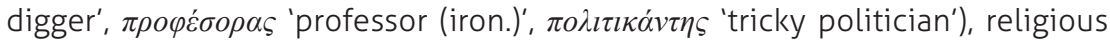

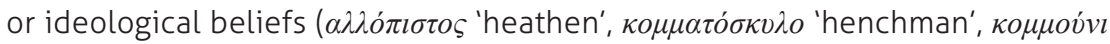


'commie'), or racial or ethnic group ( $\alpha \rho \alpha \dot{\pi} \eta \varsigma$ 'nigger', $\mu \pi \alpha \sigma \tau o v v o ́ \beta \lambda \alpha \chi o \varsigma$ ' 'hillbillies'). Additionally, insults may comment on supposed inadequacies of someone's family or friends ( $\kappa \varepsilon \rho \tau \alpha \dot{c} \varsigma$ 'cuckold').

It is worth pointing out that a large number of the terms of abuse derive on nouns denoting 1 . animals that are conventionally associated with unpleasant

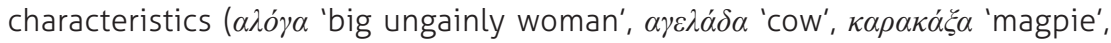

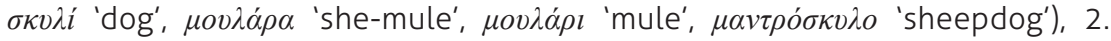
tabooed bodily organs, effluvia and sexual behaviours ( $\alpha \rho \chi i \delta l$ 'prick', $\mu$ ovvi

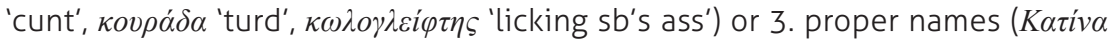

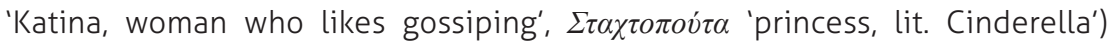
(cf. for example, Allan \& Burridge 2006; Kechagia 1997; Labov 1978). Finally, it should be noticed that a taboo word or a term of abuse may have several uses, which vary from insult to intimacy and solidarity. In everyday conversations one can find examples where apparent terms of abuse (ex. $\mu \alpha \lambda \alpha \dot{\alpha} \alpha \varsigma$ 'asshole') are used in a humorous way to display friendship or affection to someone close to the speaker (Allan \& Burridge 2006; Crystal 1995; Kechagia 1997;

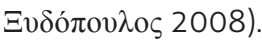

\subsection{Labeling of Insulting Words in Dictionaries}

Although taboo and insulting words are extremely frequent in everyday conversation, particularly of young people, it took dictionary writers some time to decide to include these words in their headwords (entries) (Bejoint 2000; Landau 2001). According to Landau (2001), dictionary labelling of insult is essentially political and moral. If a general purpose dictionary needs to be commercially successful, it must reflect the ideological values of its public (Béjoint 2000). On the other hand, according to Béjoint (2000: 129), the more recent a dictionary is, the more liberal it is. According to him, all contemporary general purpose dictionaries in all countries move towards greater liberalism in the inclusion of taboo or offensive words (Béjoint 2000: 127)². Most modern dictionaries try to warn the potential user against the offensive character of these words by using usage labels, like derogatory, offensive, disparaging, etc. Nevertheless, as already mentioned in the literature (Abecassis 2008; Landau

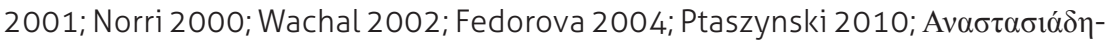

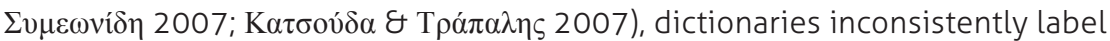

$\mathbf{2}$ It seems also that the decision whether to include or not to include offensive words in a dictionary relates also to the purpose of the dictionary, i.e. whether the dictionary is descriptive or has normative or pedagogical aims (Landau 2001: 230). 
taboo and insulting words such as 'colloquial', 'informal', 'derogatory', sexist, etc. On the other hand, as Landau (2001: 233) observes, there are no agreedupon criteria for characterizing some usages as offensive or abusive. Labels cannot tell us everything about the degree of offensiveness of specified terms under specific conditions (cf. Landau 2001). Furthermore, Norri's study on English dictionaries revealed that with certain semantic categories (terms for nationality or race, terms for stupidity and terms for deceitfulness) the likelihood of uniform treatment is greater than with others (ex. terms for sexual orientation, physical appearance, arrogant or aggressive behavior) (cf. Norri 2000: 91). In addition, one of Norri's findings was that terms for nationality are consistently accompanied by a 'negative' in at least sixty per cent of the entries and that the percentage of labeling is radically smaller in the semantic categories that refer to unintelligent or deceitful people. Finally, it is worth noting that usage labels have recently received renewed attention in Modern

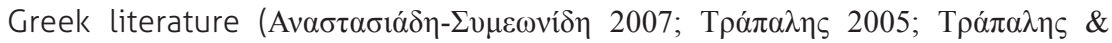

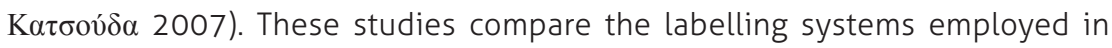
Modern Greek dictionaries, point out the problems emerging from their use and proceed to suggestions for the creation of labelling systems which would be more functional.

\section{Labeling of Insulting Words in the LKN and the LNEG2}

As already mentioned in the introduction, the purpose of the present paper is to survey the treatment of 'negative' terms in two Modern Greek dictionaries, namely the LNEG2 and the LKN. The main hypothesis is that negative label usage in dictionaries varies according to the semantic class of the entry. We also expect variation in the labeling of the same negative words between the LNEG2 and the LKN.

\subsection{Data Description}

For the corpus elaboration of the present study first we automatically extracted all the entries of the letters A, K, M, П, $\Sigma$ marked with the labels

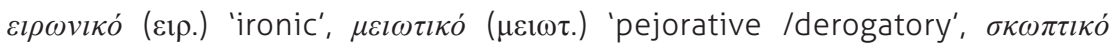

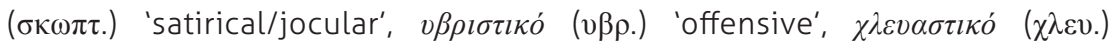

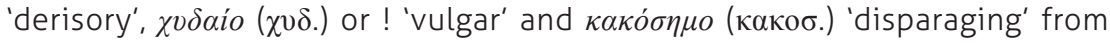
the online version of the LKN (http://www. komvos.edu.gr/dictionaries/ dictonline/DictOnLineTri.htm) and from the LNEG2. The extraction provided 
543 entries. Then an ACCESS data base was created including each entry followed by the labels used in the two dictionaries for each entry. Since very often the negative sense of a word is conveyed by the definition of that word without the use of special labels, we undertook a second extraction of

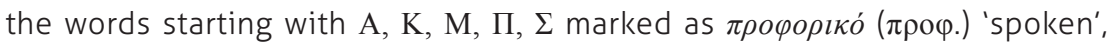

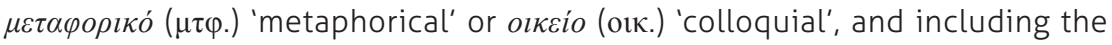

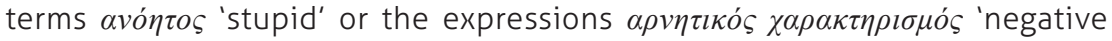

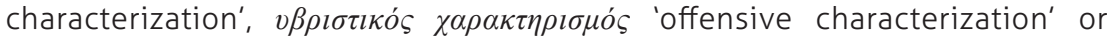

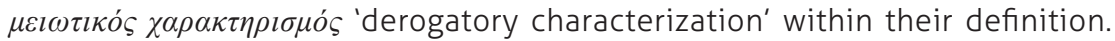
The new extraction provided another 162 entries.

In a second phase the entries were classified according to their meaning in the following categories:

- words evaluating nationality / racial or cultural group

- words evaluating mental abilities

- words evaluating appearance (ugliness, weight)

- words evaluating behavior

- words evaluating political beliefs

- words evaluating sexual orientation

- derogatory words for women or men

- words relating to sex (terms for the organs and acts of sex)

- words denoting bodily effluvia

- words evaluating the age of a person or an object

- words relating to religion

- words relating to diseases or disabilities

From the total 705 entries only 331 were classified in the above mentioned categories. These words constituted our final corpus.

\subsection{Results}

\subsubsection{Labeling Comparison between the LKN and the LNEG2}

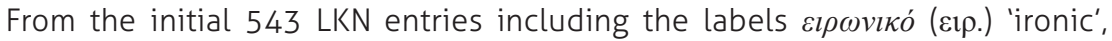

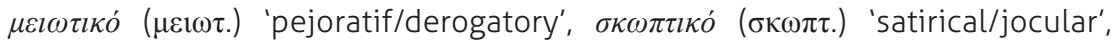

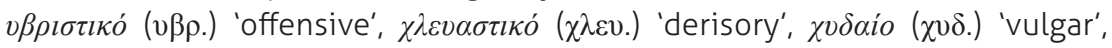
ккко́бпно (какоб.) 'disparaging' and! the LNEG2 had separate labels only for 242 words. 124 of the 543 shared the same label with the equivalent entry in the LKN. Table 1 presents the frequency of labels used in the LKN and the LNEG2 entries of our sample. 
Table 1.

Frequency of labels in the LKN and the LNEG2

\begin{tabular}{|c|c|c|c|c|}
\hline LABELS & LKN & PERCENTAGE & LNEG2 & PERCENTAGE \\
\hline Iron. & 185 & $34 \%$ & 43 & $17,8 \%$ \\
\hline Pej. & 256 & $47,1 \%$ & 91 & $37,6 \%$ \\
\hline Satir. & 10 & $1,8 \%$ & 24 & $9,9 \%$ \\
\hline Off. & 51 & $9,3 \%$ & 26 & $10,7 \%$ \\
\hline Der. & 21 & $3,8 \%$ & - & $0 \%$ \\
\hline Vulg. & 31 & $5,7 \%$ & - & $0 \%$ \\
\hline Disp. & - & $0 \%$ & 33 & $13,6 \%$ \\
\hline$!$ & - & $0 \%$ & 25 & $10,3 \%$ \\
\hline TOTAL & $\mathbf{5 4 3}$ & $\mathbf{1 0 0} \%$ & $\mathbf{2 4 2}$ & $\mathbf{1 0 0 \%}$ \\
\hline
\end{tabular}

As was expected differences were found in the labeling systems for derogatory words in the LKN and the LNEG2. This finding is consistent with previous research

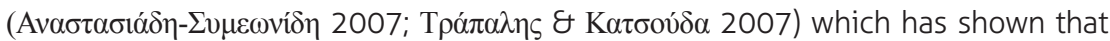
labelling systems in Modern Greek dictionaries differ in respect to the number of lexicographic labels and the way they are used. In many entries of our sample no labels are used in the LNEG2 for words that are labelled, the LKN as for example in

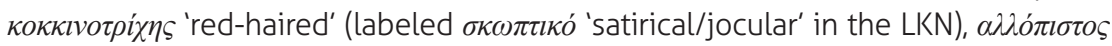

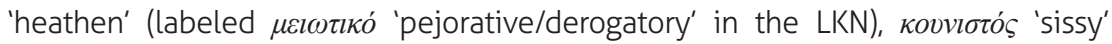

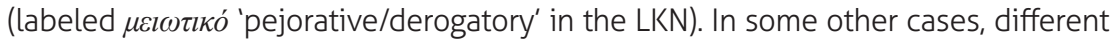
labels described the same entries, as for example $\pi \alpha \tau \sigma \alpha \beta o v$ o $\alpha$ 'slut' (labeled

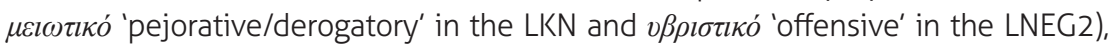

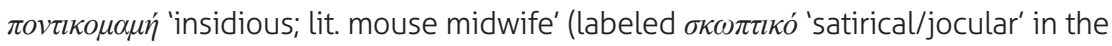

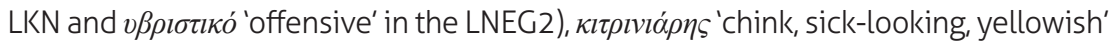

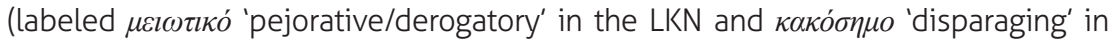
the LNEG2). Finally from the 124 entries which shared the same labels in the LKN

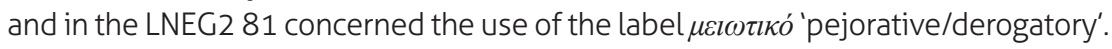

On the other hand, as we can see in Table 1 , there is unanimity as far as the frequency of use of various labels in the two dictionaries is concerned. More precisely, the most frequent negative label both in the LKN and in the LNEG2 is

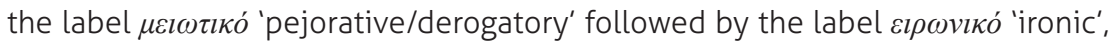

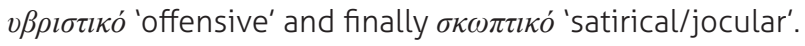

\subsubsection{Distribution of Labels According to Semantic Categories}

Tables 2 and 3 present the distribution of labels into semantic categories in the LKN and the LNEG2, respectively. 
Major Trends in Theoretical and Applied Linguistics

Table 2.

Distribution of labels into semantic categories in the LKN.

\begin{tabular}{|l|c|c|c|c|c|c|c|c|c|c|c|}
\hline CATEGORIES & Iron. & Pej. & Sat. & Off. & Deris. & Vulg & Spok. & Met. & Coll. & Def. & total \\
\hline Nationality & & 7 & & 1 & 1 & & & & & & 9 \\
\hline Mental abilities & 4 & 3 & & & & & 2 & 3 & 17 & 6 & 35 \\
\hline Appearance & 9 & 18 & 2 & 1 & & & 4 & & 3 & 10 & 47 \\
\hline Behavior & 21 & 40 & & 10 & 3 & 5 & 4 & 3 & & 29 & 115 \\
\hline Political beliefs & 1 & 15 & & 2 & & & & & & 4 & 22 \\
\hline $\begin{array}{l}\text { Sexual } \\
\text { orientation }\end{array}$ & 2 & 4 & 1 & 10 & & 1 & & 3 & & 16 & 37 \\
\hline $\begin{array}{l}\text { Derogatory words } \\
\text { women/ men }\end{array}$ & 2 & 2 & & & & 8 & 2 & 1 & & & 13 \\
\hline Sex & 2 & 2 & & 1 & & 9 & 3 & & & 1 & 18 \\
\hline Bodily effluvia & 3 & 8 & 1 & 2 & 1 & 1 & & & & & 16 \\
\hline Age & 2 & 3 & & 1 & & & & & & & 6 \\
\hline Disease & & & & & & & & & & \\
\hline Religion & & & & & & & & & & & \\
\hline
\end{tabular}

Table 3.

Distribution of labels into semantic categories in the LNEG2.

\begin{tabular}{|l|c|c|c|c|c|c|c|c|c|c|c|c|}
\hline CATEGORIES & Iron. & Pej. & Sat. & Off. & Disp. & ! & Spok. & Met. & Coll. & 0 & Def. & total \\
\hline Nationality & & 2 & 1 & 1 & 1 & & & & & 2 & 2 & 9 \\
\hline Mental abilities & 1 & 5 & 1 & 4 & & & & 7 & 1 & & 16 & 35 \\
\hline Appearance & 1 & 23 & 5 & 1 & & 2 & & 2 & & & 13 & 47 \\
\hline Behavior & 5 & 17 & 5 & 10 & 8 & 10 & & 13 & & 12 & 35 & 115 \\
\hline Political beliefs & 1 & 11 & & & 2 & & & & & 3 & 3 & $20 *$ \\
\hline $\begin{array}{l}\text { Sexual } \\
\text { orientation }\end{array}$ & 1 & & & & 1 & & & & 1 & 2 & 5 \\
\hline $\begin{array}{l}\text { Derogatory words } \\
\text { women/ men }\end{array}$ & 1 & 3 & & 10 & & 6 & & 4 & & & 14 & 37 \\
\hline Sex & 1 & 3 & 1 & 4 & 1 & 1 & & 2 & & 3 & & 16 \\
\hline Bodily effluvia & & 1 & 1 & & & 9 & & & 3 & 1 & 1 & $16 *$ \\
\hline Age & 5 & & & & & & & & 1 & & 9 \\
\hline Disease & & 1 & & & & & & & & 5 & 6 \\
\hline Religion & & & & 8 & & & & & 4 & 13 \\
\hline
\end{tabular}




\section{A. Words Evaluating Nationality / Racial or Cultural Group}

Three out of the seven sample words for nationalities share the same label in both

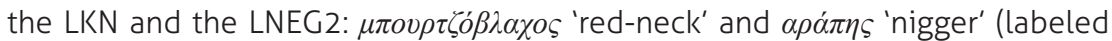

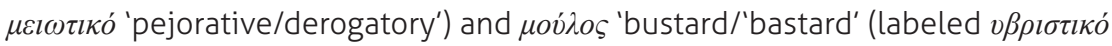

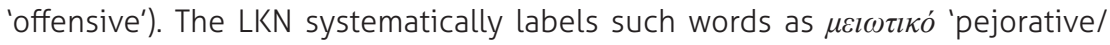

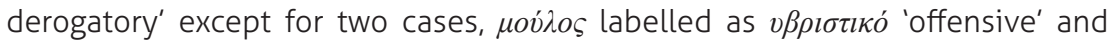

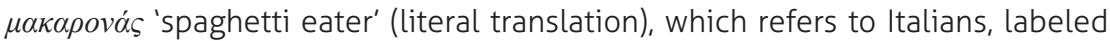
as $\chi \lambda \varepsilon v \alpha \sigma \tau \imath \kappa o$ ' 'derisory'. The labelling policy of the LNEG2 is not that systematic. In some cases there is neither a label nor a description of the negativity within the definition (e.g. $\alpha \rho v \alpha o v i \eta \eta \varsigma^{\prime}$ 'bungler'). In some others (e.g. $\alpha \rho \alpha \pi i \alpha$ 'nigger land', $\alpha \rho \beta \alpha$ vitn s 'arvanites') the negativity of the term is expressed in the definition.

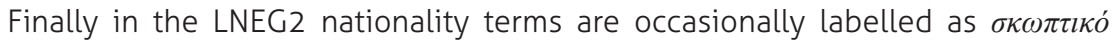

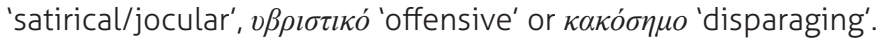

\section{B. Words Evaluating Mental Abilities}

The labeling tendency in the LKN for words evaluating mental abilities is to characterize them as oiksio 'colloquial', whereas in the LNEG2 there is a systematic description of the negativity of such terms within the word definition. Some

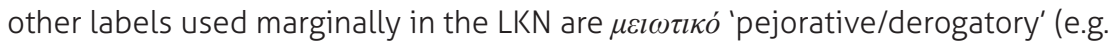

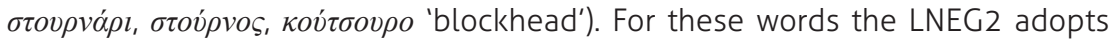

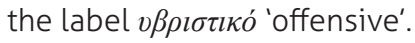

\section{Words Evaluating Appearance (Ugliness, Weight)}

As can be noticed in Tables 2 and 3, both the LKN and the LNEG2 have the

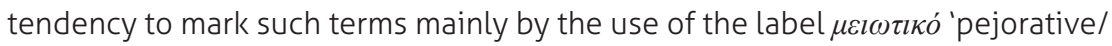
derogatory' or by describing the negativity in the entry definition. The LKN also

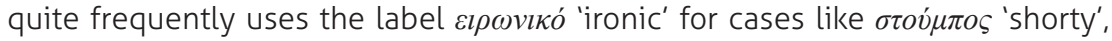

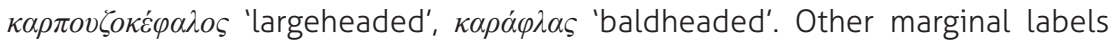

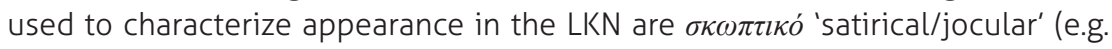

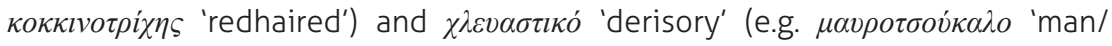

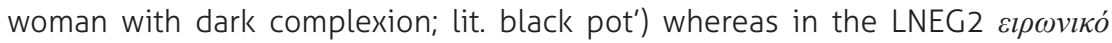
'ironic' (e.g. $\sigma \tau o v ́ \mu \pi o \varsigma$ 'shorty') and! (e.g. $\kappa \omega \lambda \alpha \rho o v$ 'fat ass').

\section{Words Evaluating Behavior}

The majority of our sample words evaluating behavior receive in the LKN the

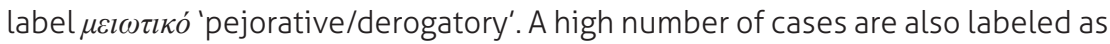

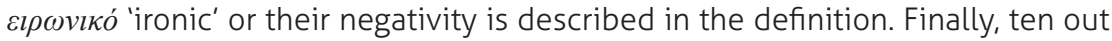

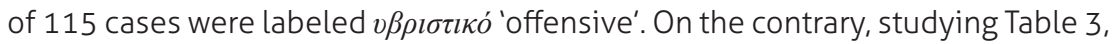


it could be claimed that no clear tendency is adopted in the LNEG2: while the majority of such entries are marked for their negativity with information provided in the definition, however there is use of a wide range of labels, such

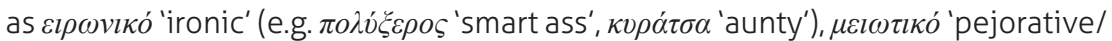

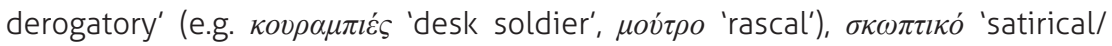

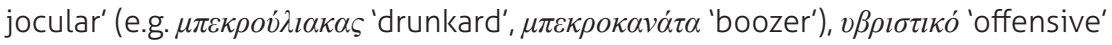

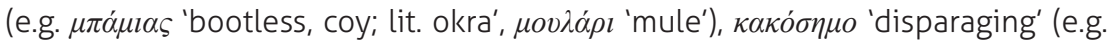

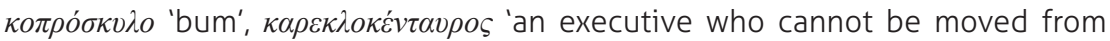

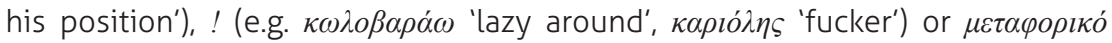

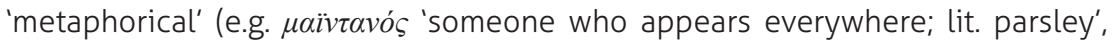
$\sigma \pi \alpha \dot{\rho} \rho \varsigma$ 'lazybones'). Finally, the LNEG2 provides neither labels nor negative description in the definition for 12 out of 115 entries.

\section{E. Words Evaluating Political Beliefs}

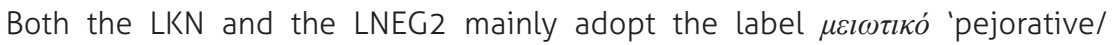
derogatory' for words evaluating someone's political beliefs (e.g

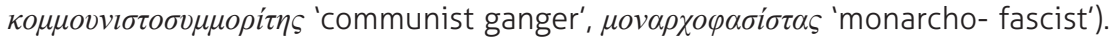
This unanimity could be attributed to the fact that use conditions of such words are unambiguous; the intention of a speaker who uses such words is to express in a strongly contemptuous way his negative opinion of the other in order to offend him.

\section{F. Words Evaluating Sexual Orientation}

From the five sample words the three are described through the label $\mu \varepsilon \imath \omega \tau \imath \kappa o ́$

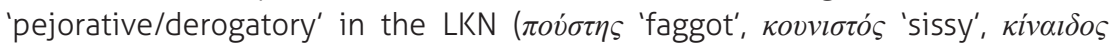

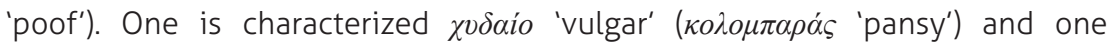

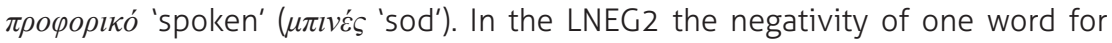
sexual orientation is described in the definition as slang ( $\alpha \rho \gamma \kappa o ́) ~(\kappa о \lambda о \mu \pi \alpha \rho \alpha \dot{s}$

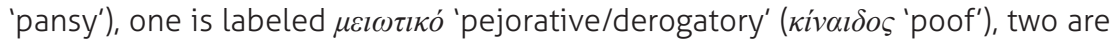

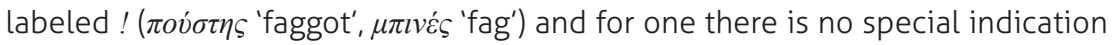

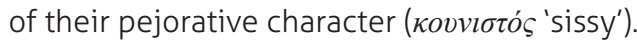

\section{G. Derogatory Words for Women or Men}

Our data show that derogatory words for women or men are usually labeled

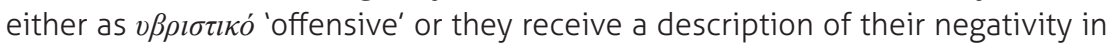
their definition both in the LKN and in the LNEG2. Quite frequent in the LNEG2

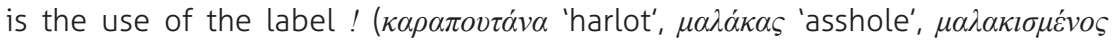

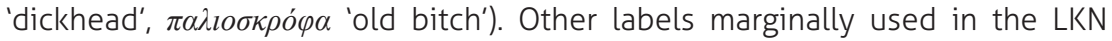

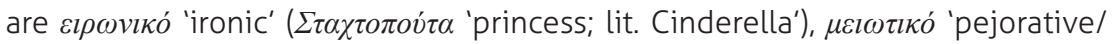




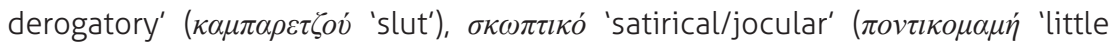

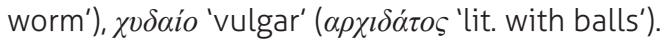

\section{H. Words Relating to Sex (Terms for the Organs and Acts of Sex) / Bodily Effluvia}

Both dictionaries agree in labeling words relating to sex or bodily effluvia as

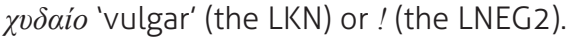

\section{Words Evaluating the Age of a Person or an Object}

The LKN mainly labels words evaluating the age of someone as $\mu \varepsilon \imath \omega \tau \imath \kappa o ́$

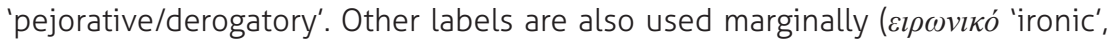

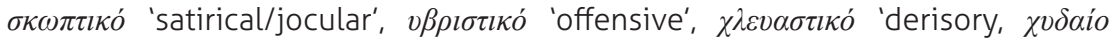
$(\chi \vee \delta$.) 'vulgar'). The LNEG2 makes no systematic use of a wider range of labels

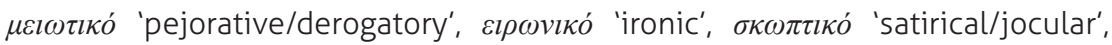

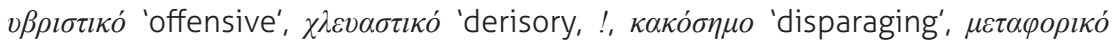
'metaphorical', etc.

\section{J. Words Relating to Religion}

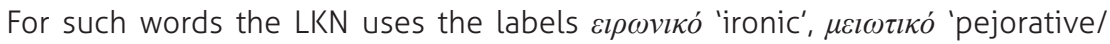

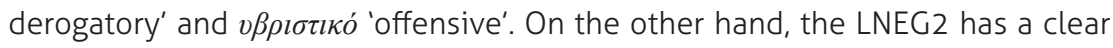
tendency to provide negative description in the lemmas' definitions.

\section{K. Words Relating to Diseases or Disabilities}

Finally derogatory terms for diseases or disabilities are described in the LKN

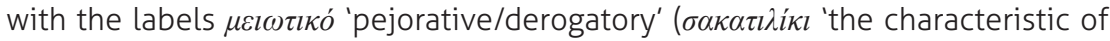

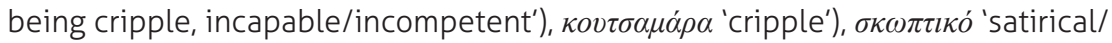

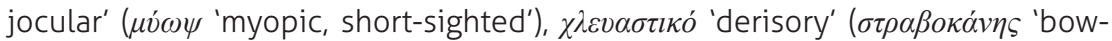

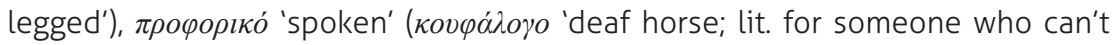

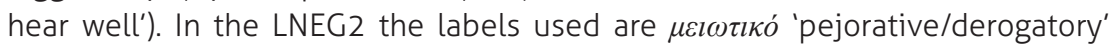

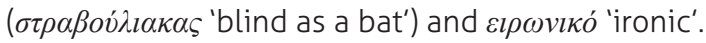

\section{Conclusions}

In this paper we surveyed the treatment of 'negative' terms in two Modern Greek dictionaries, the LNEG2 and the LKN. The investigation of the treatment of these terms has revealed that 1 . the distinction made in the prefaces between derogatory, offensive, slang or taboo words is hard to maintain, 2. dictionaries 
Major Trends in Theoretical and Applied Linguistics

do not always agree in the labeling of the same negative words, 3 . there is a wide range of possible descriptions of negative usage, and 4. the likelihood of a 'negative' indication varies from one semantic group to another. Finally, we notice that these findings are consistent with Norri's (2000) findings about usage labeling in English dictionaries. 


\section{References}

Abecassis, M. 2008. The Ideology of the Perfect Dictionary: How Efficient can a Dictionary be? Lexikos 18: 1-14.

Allan, K. and K. Burridge. 2006. Forbidden Words: Taboo and the Censoring of Language. Cambridge: Cambridge University Press.

Béjoint, H. 2000. Modern Lexicography. An Introduction. Oxford: Oxford University Press.

Crystal, D. 1995. The Cambridge Encyclopedia of the English Language. Cambridge: Cambridge University Press.

Fedorova, I. 2004. Style and Usage labels in Learner's Dictionaries: Ways of Optimization. Euralex 2004 Proceedings, 265-272. Available at: http://www.euralex.org/elx_proceedings/Euralex2004/027_2004_V1_ Irina\%20V.\%20FEDOROVA_Style\%20and\%20usage\%20labels\%20in\%20 learners\%20dictionaries_Ways\%20of\%20optimisati.pdf

Kechagia, A. 1997. Insulting words in Modern Greek. In Proceedings of the 2nd International Conference on Greek Linguistics. Graz: Neugebauer Verlag, 297-304.

Labov, W. 1978. Le parler ordinaire: la langue dans les gettos noirs des Etats-Unis. (Language in the Inner City) transl. by A. Kihm. Paris: Minuit.

Landau, S. 2001. $2^{\text {nd }}$ edition. Dictionaries. The Art and Craft of Lexicography. Cambridge: Cambridge University Press.

Mercury, R.-E. 1995. Swearning: a 'bad' part of language; A 'good' part of language learning. TESL Canada Journal 13(1): 28-36. 
Norri, J. 2000. Labelling of Derogatory Words in Some British and American Dictionaries. International Journal of Lexicography 13(2):71-106.

Ptaszynski, M.O. 2010. Theoretical Considerations for the Improvement of Usage Labelling in Dictionaries: A Combined Formal-Functional Approach. International Journal of Lexicography 23(4): 411-442.

Wachal, R. 2002. Taboo or not taboo? That is the question. American Speech 77(2):195-206.

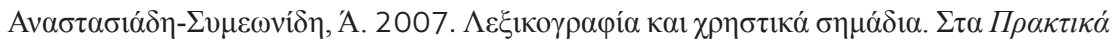

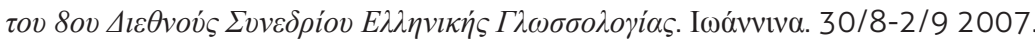

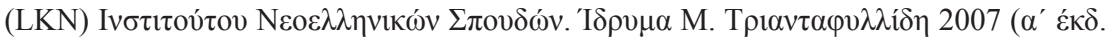

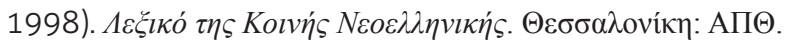

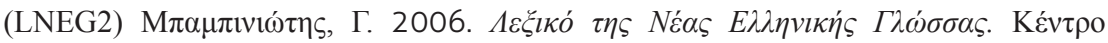
$\Lambda \varepsilon \xi$ ıколоүías.

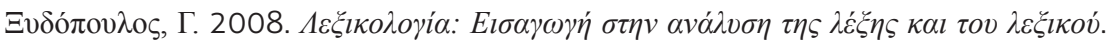

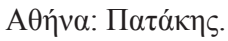

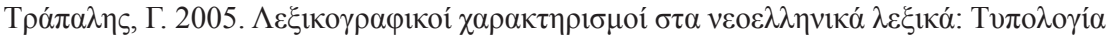

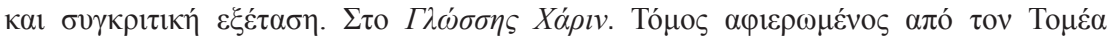

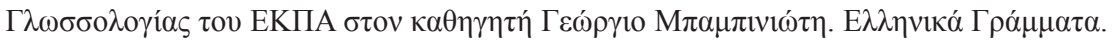
2008. 664-678.

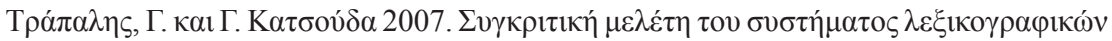

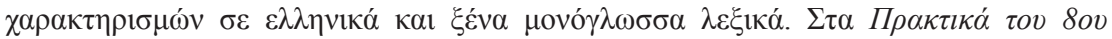

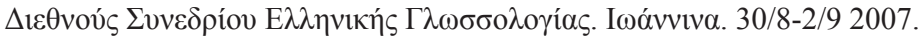

